\title{
What works in genomics education: outcomes of an evidenced-based instructional model for community-based physicians
}

\author{
E. Kate Reed, MPH, ScM, CGC ${ }^{1,5}$, Katherine A. Johansen Taber, PhD2, Therese Ingram Nissen, MA ${ }^{1,5}$, \\ Suzanna Schott, ScM, CGC ${ }^{1,5}$, Lynn O. Dowling, MA, MBA ${ }^{3,5}$, James C. O'Leary, MBA ${ }^{4}$, and \\ Joan A. Scott, MS, CGC ${ }^{1}$
}

\begin{abstract}
Purpose: Education of practicing health professionals is likely to be one factor that will speed appropriate integration of genomics into routine clinical practice. Yet many health professionals, including physicians, find it difficult to keep up with the rapid pace of clinical genomic advances and are often uncomfortable using genomic information in practice.
\end{abstract}

Methods: Having identified the genomics educational needs of physicians in a Silicon Valley-area community hospital, we developed, implemented, and evaluated an educational course entitled Medicine's Future: Genomics for Practicing Doctors. The course structure and approach were based on best practices in adult learning, including interactivity, casebased learning, skill-focused objectives, and sequential monthly modules.
Results: Approximately 20-30 physicians attended each module. They demonstrated significant gains in genomics knowledge and confidence in practice skills that were sustained throughout and following the course. Six months following the course, the majority of participants reported that they had changed their practice to incorporate skills learned during the course.

Conclusion: We believe the adult-learning principles underlying the development and delivery of Medicine's Future were responsible for participants' outcomes. These principles form a model for the development and delivery of other genomics educational programs for health professionals.

Genet Med advance online publication 19 November 2015

Key Words: continuing medical education; education; genetic; genomic; physician
The appropriate integration of genomics into routine practice stands to significantly impact medicine. ${ }^{1}$ However, substantial barriers must be overcome to drive the integration of genomic technologies to clinical care. One is the gap in genetics knowledge and skills among physicians. ${ }^{2-5}$ Despite a consistently positive view among physicians about the importance of genomics in medicine, ${ }^{5}$ many lack contemporary background knowledge in genetics and are not adequately prepared to use genetic information to treat patients. ${ }^{5-7}$ A noted lack of confidence about their own genetics knowledge has prevented physicians from having comprehensive discussions about it with their patients. ${ }^{8}$ Furthermore, physicians may order genetic testing that is inappropriate for the clinical situation and that they do not correctly interpret, potentially leading to wasted health-care resources and less than optimal patient outcomes. ${ }^{9,10}$ Physicians also have reported a lack of understanding about when and how to make referrals for genetic counseling. ${ }^{11,12}$

Physicians have endorsed the need for more training in areas such as genetic risk assessment, test ordering and interpretation, and counseling., ${ }^{5,7}$ Many groups have developed continuing education programs designed to address these topics. ${ }^{13-16}$ Historically, though, much continuing medical education (CME) has been passive and didactic. ${ }^{17}$ Programs that are grounded in evidence-based principles of adult learning and medical education have a greater impact on physician performance than programs that do not incorporate such principles. ${ }^{18-20}$ The strongest gains are seen in CME activities that are more interactive, use a variety of instructional techniques, involve multiple exposures, and focus on outcomes considered important by physicians. ${ }^{21,22}$ Not all educational activities are developed with the goal of impacting practice change. ${ }^{1,17}$ The Accreditation Council for Continuing Medical Education has reported that, of activities offered by its accredited CME providers in 2014, slightly more than half were designed to change performance and only $43 \%$ were analyzed to determine their impact on performance. ${ }^{23}$

Given the need for education designed to support practice change, the National Coalition for Health Professional

${ }^{1}$ National Coalition for Health Professional Education in Genetics, Lutherville, Maryland, USA; ${ }^{2}$ Division of Science and Biotechnology, American Medical Association, Chicago, Illinois, USA; ${ }^{3}$ Genomic Medicine Institute, El Camino Hospital, Mountain View, California, USA; ${ }^{4}$ Genetic Alliance, Washington, District of Columbia, USA. ${ }^{5}$ Current affiliation: Department of Clinical and Continuing Education, The Jackson Laboratories, Bar Harbor, Maine, USA (E.K.R., T.I.N., and S.S.); Dowling Associates, San Diego, California, USA (L.O.D.). Correspondence: E. Kate Reed (kate.reed@jax.org) 
Education in Genetics, Genetic Alliance, and the American Medical Association partnered with a community hospital that had identified the need for and motivation among its physicians to improve genomics knowledge and skills. Using evidencebased adult-learning principles as a framework, along with data collected from an institutional advisory committee and a pilot program, a genomics educational program for physicians at El Camino Hospital (ECH) in Mountain View, California, was developed, implemented, and evaluated. The goal of the 10-module, in-person program, entitled Medicine's Future: Genomics for Practicing Doctors (referred to as Medicine's Future), was to train ECH physicians to be confident incorporating genetic principles into routine care.

\section{DEVELOPMENT AND IMPLEMENTATION OF MEDICINE'S FUTURE}

\section{Inception and content development}

The ECH Genomic Medicine Institute (GMI) advisory board identified an institutional need for physicians who could demonstrate competence in basic genetics skills and knowledge. In 2011, it released a request for proposals to fund the development of a program to address this need. The National Coalition for Health Professional Education in Genetics and the Genetic Alliance-groups with expertise in health professional education and patient advocacy, respectively-were selected. Needs assessment and current practice data were gathered through a project-specific GMI advisory committee that included ECH leadership and physicians. The process revealed that the outcomes of interest were improvements in foundational genomics clinical skills and knowledge, including collecting family history and assessing risk, assessing clinical validity and utility of genetic testing for specific clinical situations, ordering and interpreting genetic tests, and integrating genetic information into management decisions. A case-based, patientcentered approach was deemed to be important to providers. Foundational modules were developed to introduce these skills using a variety of conditions and case studies. Subsequent modules were developed to focus on application of the foundational skills to several conditions, including common diseases, pharmacogenomics, cancer, neurology, cardiology, pediatrics, and prenatal genetics.

\section{Instructional design and delivery of the Medicine's Future curriculum}

The design of the workshop curriculum was rooted in Merrill's First Principles of Instruction, a set of prescriptive problembased learning principles that are common to instructional design theories. ${ }^{24,25}$ The principles promote learning when (i) learners are engaged in solving real-world problems, (ii) existing knowledge is activated as a foundation for new knowledge, (iii) knowledge is demonstrated to the learner, (iv) new knowledge is applied by the learner, and (v) new knowledge is integrated into the learner's world. The application of Merrill's First Principles to the Medicine's Future curriculum is summarized in Table 1. Each 2-hour module included a model case study in which an expert facilitator led large-group discussion through the case, small-group cases to practice application, and a patient video with large-group discussion to incorporate concepts related to patient experiences.

To further improve learning outcomes, the training was sequenced over several months to capitalize on learn-worklearn opportunities, which are characterized by learning events followed by application in practice and expert feedback. ${ }^{26}$ The training incorporated methods including elements of narrative medicine, cognitive apprenticeship, collaborative learning, point-of-care job aids, and ultimately community of practice. ${ }^{27}$ Each module used evidence-based active-learning strategies including peer discussion, expert feedback, audience response systems, and case-based problem solving, which support retention, transfer, conceptual understanding, and improved attitudes. ${ }^{28-31}$ In addition, videos of individuals affected by genetic conditions talking about their experience with the condition and interactions with health-care providers were included in every session. These experiences were used to explore the impact of genetic information on patients and family members.

Once developed, the Medicine's Future curriculum was piloted at ECH from September 2011 through June 2012, with a 2-hour module presented monthly. All ECH physicians were invited to attend the course. Formative evaluation was conducted after each module, at the midpoint of the curriculum, and at the end of the pilot period. Modifications to the curriculum focused on unifying instructional messages, selecting and training facilitators, simplifying genetic testing methodologies, and increasing opportunities to practice risk stratification. The revised Medicine's Future curriculum, on which we report in this article, was offered monthly from October 2013 through July 2014. As with the pilot curriculum, all physicians at ECH were eligible to participate in the course. Supplementary Table S1 online lists the title and main focal points of each module. A clinical geneticist facilitated each 2-hour module, leading discussions and interactive case studies. Each module was awarded a maximum of 2.0 AMA Physician Recognition Award Category 1 Credits. Participants attending and completing a postactivity assessment and evaluation were eligible to claim CME credit.

\section{Data collection and evaluation}

Enrollees in the revised Medicine's Future program were asked to complete a preactivity assessment approximately 1 week before the first module was presented. This assessment, administered through the American Medical Association's Online Learning Center, consisted of 5 demographic questions, 12 Likert-type questions about current genetics-related practice experiences and behaviors, 14 semantic differential-scale questions exploring attitudes about genetics in medicine and confidence in genetics-related practice skills, and 20 multiple-choice questions testing knowledge of genetics concepts. These questions were a combination of items used in a similar audience and items developed specifically to assess concepts related to 
Table 1 Merrill's First Principles of Instruction as applied to Medicine's Future instructional strategies Merrill's First Principles of Instruction

Solving real-world

Knowledge and skills were embedded into relevant clinical scenarios, providing authentic context to the content and problems allowing learners the opportunity to apply the new skills and integrate them with existing skills and knowledge in a structured, reflective approach. Learners trained in such an environment are more able to transfer knowledge and skills to a new situation. 39,40

Activating existing knowledge

Existing knowledge was activated by utilizing familiar provider knowledge and skills in risk assessment, predictive and diagnostic testing, and patient-centered communication. Case studies were designed to augment those skills by adding genetic information. Additionally, learning was sequenced with each of the 10 modules building on and reinforcing skills from the previous module.

Demonstration

Demonstrations were provided to the whole group by working through model clinical scenarios facilitated by a clinical expert providing guidance. Discussions were framed by clinical questions that were answered using an audience response system. Patient videos supplemented concepts in the model demonstration and were followed by group discussion of salient communication and counseling messages.

Application Small groups worked on problem-based case studies to practice skills demonstrated in the large group. This was followed by large-group discussions designed to integrate the collaborative learning with expert coaching.

Integration

After each module, homework assignments provided an opportunity to implement what was learned in the clinic followed by discussions at the beginning of each subsequent session to debrief any questions or problems encountered during implementation. Additionally, monthly case conferences helped establish a community of practice at the conclusion of the workshop series and provided a means of ongoing support and reinforced skills transfer.

this curriculum's desired outcomes. Items were piloted with the 2011-2012 modules. Knowledge items with limited or no spread were dropped or modified. Three new items were created to reflect the revised content's increased focus on pharmacogenomics. The preactivity assessment questions are in Supplementary Figure S1 online.

Postactivity assessment and evaluation were administered through the American Medical Association's Online Learning Center following each module. Assessment questions consisted of the same questions exploring attitudes and confidence as those encountered in the preactivity assessment. All postactivity knowledge questions were drawn from the 20 knowledge questions from the preactivity assessment. For modules 1 through 9, 3 or 4 multiple-choice knowledge questions were included in the postactivity assessment; for module 10, $10 \mathrm{mul}$ tiple-choice knowledge questions were included. Evaluation questions asked about the general effectiveness of the module and whether and how participants intended to change their practice based on it. Approximately 6 months after module 10 was complete, an online survey was sent to participants containing a subset of attitude, confidence, and knowledge questions previously encountered, as well as four new questions about changes in practice behaviors due to Medicine's Future. Genetic counseling referral data were collected by assessing the genetic counseling utilization and billing records of the ECH GMI, which administered the counseling program.

\section{Data analysis}

Participants' responses on each of the assessments and the 6-month follow-up survey were aggregated and compared to determine changes in attitudes about genetics in medicine and confidence in genetics-related practice skills. For semantic differential-scale questions, categories at the high and low ends of the scale were combined. For example, on a scale of 1 to 5 where $1=$ strongly disagree and $5=$ strongly agree, responses of 4 and
5 were combined. To determine significance, the Fisher's exact test was used; differences were considered significant when $P<0.05$. To analyze genetics knowledge gains, the number of correct answers on the preactivity assessment was compared with the number of correct answers to the same questions on postactivity assessments following each module and 6 months after module 10. Additionally, to determine knowledge gains in broad genetics-related practice components, questions were categorized into the topic areas of risk assessment, development of testing strategy, test interpretation, and application of results to patient care, and the number of correct answers to questions in each of these categories on the preactivity assessment was compared with the number correct on postactivity assessments. To determine significance, a chi-squared test was used; differences were considered significant when $P<0.05$.

\section{Participants}

\section{RESULTS}

Participant demographic and practice characteristics are summarized in Supplementary Table S2 online. Thirty-four participants enrolled in the revised Medicine's Future curriculum and completed the preactivity assessment; 33 were physicians and 1 was a physician assistant. Participants represented a mix of ages, with those aged 41-50 and 61-70 years making up approximately $70 \%$ of the group. Of note, 17 specialties were represented, with more than half of the total enrollees representing primary-care specialties: family practice (5), internal medicine (8), obstetrics and gynecology (4), and pediatrics (2). Participant attendance ranged from 20 to 30 for each module. On average, 75-90\% of participants attending each module completed the postactivity assessments and evaluations. Response rate for the 6-month follow-up survey was 38.2\%.

Participants' prior experience with genetics is summarized in Table 2. Less than 20\% of participants reported receiving formal training in genetics, and approximately 30\% reported 
Table 2 Participants' experience with genetics prior to beginning Medicine's Future

Total participants $(N)$

Type of experience

$17.6 \%(6)$

Received formal genetics training in the past

Yes

$82.4 \%(28)$

No

$82.4 \%(28)$

Attended a genetics CME course, lecture, workshop, or update at a professional meeting

$\begin{array}{ll}\text { Yes } & 29.4 \%(10) \\ \text { No } & 70.6 \%(24)\end{array}$

Frequency of a genetic indication/concern arising as part of patient workup

$$
\text { Never }
$$

Several times per year

$52.9 \%(18)$

Several times per month

$14.7 \%(5)$

Several times per week

$26.5 \%(9)$

Frequency of genetics-related questions asked by patients

Never

$23.5 \%(8)$

Several times per year

$38.2 \%(13)$

Several times per month

$17.6 \%(6)$

Several times per week

$20.6 \%(7)$

Routinely reviews family history for new patients

Yes

$94.1 \%(32)$

No

$5.9 \%(2)$

Frequency of ordering genetic tests

Never

$47.1 \%(16)$

One or more times per year

$26.5 \%(9)$

One or more times per month

$14.7 \%(5)$

One or more times per week

$11.8 \%(4)$

Frequency of consultation with geneticist or genetic counselor

Never

$55.9 \%(19)$

One or more times per year

$26.5 \%(9)$

One or more times per month

$17.6 \%(6)$

One or more times per week

$0 \%(0)$

Frequency of referral to geneticist or genetic counselor

Never

$35.3 \%(12)$

One or more times per year

$47.1 \%(16)$

One or more times per month

$11.8 \%(4)$

One or more times per week

$5.9 \%(2)$

Frequency of direct consultation with genetic testing laboratory

Never

$64.7 \%(22)$

One or more times per year

$26.5 \%(9)$

One or more times per month

$8.8 \%(3)$

One or more times per week

$0 \%(0)$

Frequency of involvement in patient's direct-to-consumer genomic-risk profile testing

\section{Never}

$55.9 \%(19)$

One or more times per year

$41.2 \%(14)$

One or more times per month

$2.9 \%(1)$

One or more times per week

$0 \%(0)$

CME, continuing medical education.

having attended a continuing education course or event in genetics. The majority of participants reported a genetic concern arising among their patients several times per year; however, more than one-quarter reported concerns several times each week. Most participants reported that patients ask genetics-related questions at least several times per year, with topics frequently including family history, risk for a disease in themselves, risk for a disease in their family members, genetic etiology of a disease, genetic testing, resources for themselves or family members, and specific conditions. The vast majority of participants (94.1\%) reported that they review family history for new patients. Approximately one-quarter (26.5\%) order genetic testing more than monthly. Direct consultation with a genetics expert (geneticist or genetic counselor) or genetic testing laboratory was infrequent, with more than half reporting that they never consult. Referral of patients to genetics experts was more frequent but was not common.

\section{Knowledge related to genetics practice skills}

Significant gains in knowledge related to genetics practice skills were observed during the course. Prior to module 1, 54.6\% of participants' answers to knowledge questions were correct, whereas $85.2 \%$ of answers were correct following the module in which the question's main topic was covered $(P<0.05)$ (data not shown). To determine retention of gains, knowledge was assessed directly following module 10 and approximately 6 months after module 10. Knowledge gained was retained, as demonstrated by significant increases in correct answers to knowledge questions directly following module $10(85.0 \%)$ and 6 months after module 10 (75.0\%) compared with before module 1 ( $P<0.05$ for both; data not shown).

Throughout the 10 modules, four broad practice components were emphasized: risk assessment, development of a genetic testing strategy, test interpretation, and application of results to patient care. Significant knowledge gains were observed in all components following the module in which the concept was addressed (Figure 1). Knowledge gains were sustained throughout the course; directly following module 10 , the number of correct answers to knowledge questions in the four practice components was significantly higher compared with prior to module 1 (Figure 1). Knowledge retention in the individual practice components could not be assessed 6 months after module 10 owing to limitations in the number of questions administered at that stage.

\section{Confidence in genetics-related practice skills}

Confidence in genetics-related practice skills was self-reported by participants prior to module 1 , following each module, and 6 months after module 10. Participants were asked to rate their confidence using a scale of 1 to 5 , where 1 represented "not at all confident" and 5 represented "very confident." Self-reported confidence in eight separate practice skills significantly increased from prior to module 1 to directly following module 10 (Figure 2). Confidence in these skills increased sharply over the first four modules (data not shown). Interestingly, 


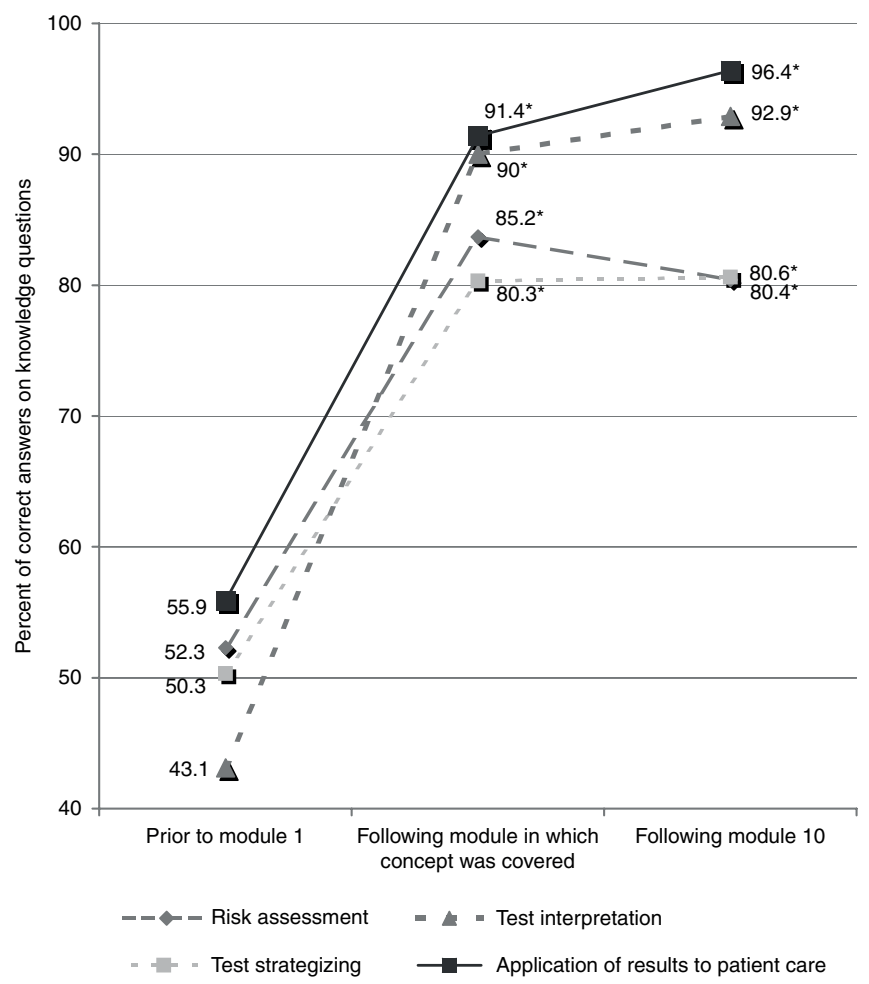

Figure 1 Change in knowledge in selected genetics concepts following the module in which the concept was covered and following module 10. Asterisks indicate statistical significance compared with values observed prior to module $1(P<0.05)$.

confidence levels had reached or were near post-module 10 levels as early as after module 4 (Figure 2). Self-reported confidence in two other practice skills - the ability to take a family history and the ability to identify patients at increased risk for a condition based on family history-showed small but insignificant increases (Figure 2).

Six months after module 10, confidence in five practice skills continued to be significantly increased. Confidence was increased compared with pre-module 1 levels, but not significantly so, for the other practice skills showing significant differences immediately following module 10 , such as the ability to order genetic testing, ability to interpret test results, and ability to use genetic information in management decisions (Figure 2).

\section{Change in practice behavior}

Following each of the 10 modules, 50.0 to $88.9 \%$ of participants reported that they planned to change their practice based on the course (Table 3); $92.3 \%$ of respondents to the 6-month follow-up survey reported that they had changed their practice based on the skills acquired during Medicine's Future (Table 3), and $92.3 \%$ of participants reported, in the form of free-text responses, that they engaged in other activities that impact genetics practice skills, including reading more journal articles about genetics, attending genetics conferences and lectures, and talking to colleagues about genetics issues more often (Table 3). Participants were asked after each module whether they believed Medicine's Future was more effective than other
CME courses in which they had engaged. On a scale of 1 to 5 , where 1 represented "much less effective" and 5 represented "much more effective," $86.2 \%$ rated effectiveness as a 4 or 5 averaged across all 10 modules (data not shown).

In addition to self-reported practice change, observed behaviors among ECH physicians suggest that Medicine's Future impacted practice change. Independently, participants from the pilot course started a monthly genetics case conference that was also attended by participants from the revised course and other $\mathrm{ECH}$ physicians. Also, in the 10 months preceding module 1, a total of 173 genetic counseling referrals were made by $\mathrm{ECH}$ physicians; during the 10 months coinciding with the course, 222 referrals were made-an increase of nearly $30 \%$ (data not shown). Referral data for the 10-month period following the course were not available.

\section{DISCUSSION}

For genetics to impact the health of the population, providers in all settings must have the skills to use genetic information to identify individuals at increased risk for disease and implement appropriate management, whether that is referral for further work-up, ordering testing, or adjusting screening regimens. We developed Medicine's Future to enhance these skills in community-based providers of many specialties. To address the known challenges of implementing genetics into practice, ${ }^{6}$ the curriculum maximized engagement through application of instructional design best principles. Our results add to the evidence that this approach was successful. ${ }^{13,14,32}$ In Medicine's Future, knowledge and confidence in practice skills related to risk assessment, development of a genetic testing strategy, interpretation of results, and application of results to patient care all improved significantly. These improvements were sustained over the 10-month duration of the course and, for some skills, for 6 months following the course. In addition, participants reported the intent to improve several genetics-related practice behaviors, and after 6 months they reported that they had changed a subset of these. Our findings are consistent with those from other education programs that show sustained improvements when the program includes substantial learnwork-learn time. ${ }^{13,32}$ For skills in which improvements were not sustained, the low frequency of opportunities to use such skills in daily clinical routines may be an explanation. For example, determining when genetic counseling is indicated is a skill that can be practiced with nearly every patient, but the need to interpret genetic test results arises much less frequently. Other studies have indicated that the ongoing use of tools to assist in triaging risk-assessment decisions at the point of care can result in longer-term practice changes. . $^{33,34}$

Beyond the quantitative measures directly related to the course objectives, we observed changes to genetic counseling referral practice and the establishment of a genetics-focused case conference. Although neither result can be directly or solely attributed to the course itself, they are associated with participants' improved confidence in identifying patients who could benefit from genetic counseling and intention to increase attendance 


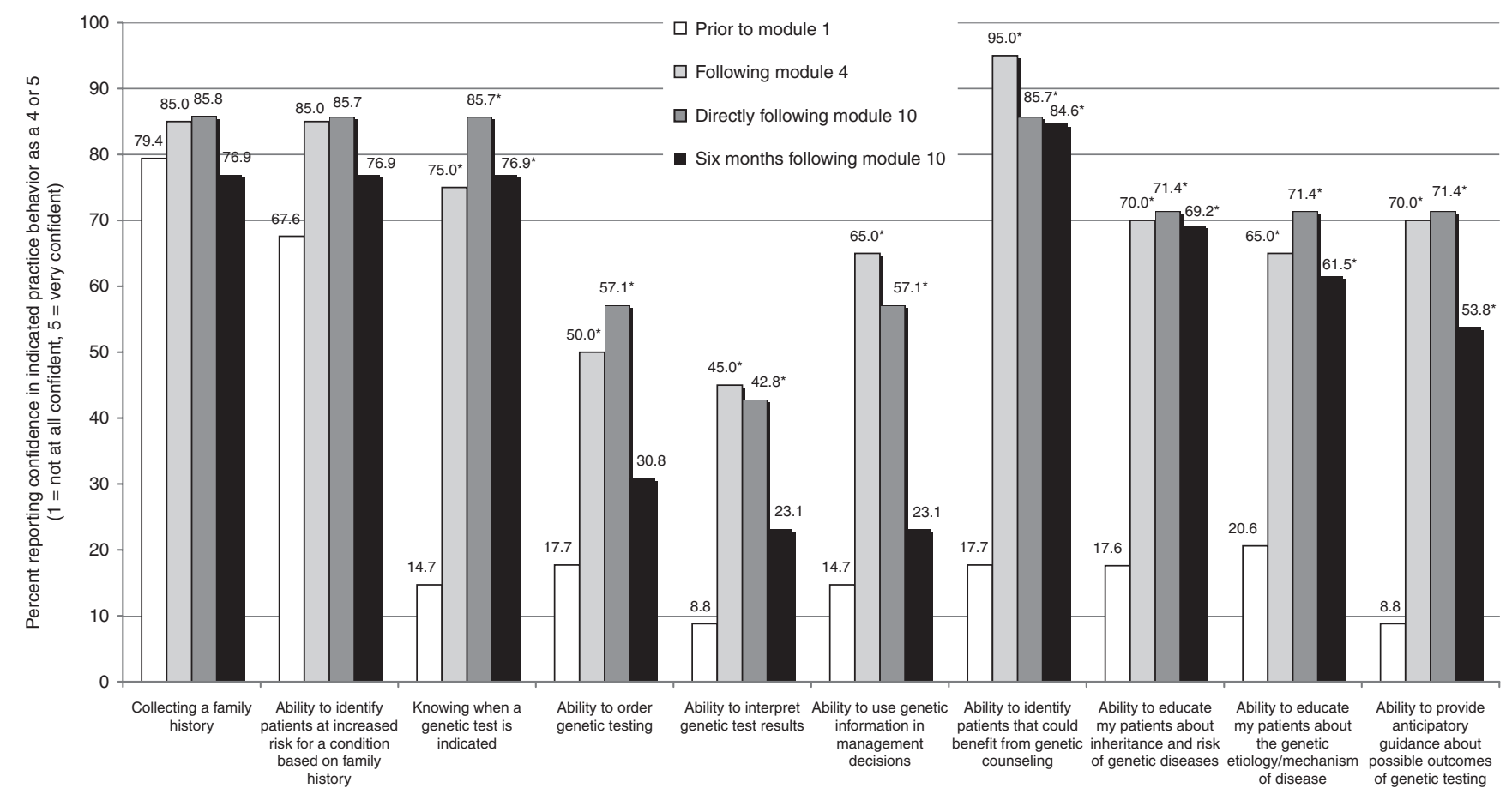

Figure 2 Confidence in practice skills related to genetics prior to module 1, following module 4, following module 10, and 6 months after module 10. Asterisks indicate statistical significance compared with values observed prior to module $1(P<0.05)$. $P$ values for nonsignificant comparisons for collecting a family history: following module $4, P=1.0$; directly following module $10, P=1.0 ; 6$ months following module $10, P=1.0$. $P$ values for nonsignificant comparisons for ability to identify patients at increased risk for a condition based on family history: following module $4, P=0.21$; directly following module $10, P=0.29 ; 6$ months following module 10, $P=0.73$. $P$ values for other nonsignificant comparisons 6 months following module 10 : ability to order genetic testing, $P=0.43$; ability to interpret test results, $P=0.33$; ability to use genetic information in management decisions, $P=0.67$.

at genetics conferences and lectures. The change in referral pattern is aligned with the larger goals that informed the development and design of Medicine's Future, namely, emphasizing risk-assessment skills to identify individuals appropriate for additional work-up and the added value of referring to genetics professionals. The spontaneous initiation of a monthly genetics case conference by attendees suggests shared interests and comfort with group learning. The development of a community of learners is one goal of adult education because it facilitates sustainable peer learning. ${ }^{35}$ We speculate that the course structure and the skill of the facilitator in encouraging discussion provided a forum for participants interested in genomics to build relationships and identify shared interests. The observed changes are particularly meaningful because they occurred within the context of a mixed population of specialties, which suggests that the foundational nature of genomic information may be one way to provide a bridge between specialists.

The identification of learners' educational needs has been demonstrated as an important component for successful outcomes, including for genomics educational programs. ${ }^{21,36}$ Because this course was intended for any physician at $\mathrm{ECH}$, it was necessary to identify common educational gaps and clinical goals across several specialties. Working with the GMI advisory board, we identified outcomes that focused on building knowledge, skills, and confidence to assess the validity and utility of genetic testing across a wide range of conditions. The course's participant mix, from primary care to nuclear medicine, suggests that these areas are of interest across specialties. This interest corresponds to an educational gap demonstrated by data showing that, prior to the course, participants correctly answered only approximately $43-56 \%$ of knowledge measures grouped by concept.

We believe that the 10-month multiple-module model of Medicine's Future contributed to its positive outcomes because it reinforced skills, provided opportunity for application in different contexts, and facilitated the development of a community of learners. Although it may not be practical in all settings to engage providers over 10 months, instructional design principles can be applied to the development of genomics education of any length or delivery type. At a minimum, the engagement of a subset of the target audience to inform objectives and skills and the use of active learning are critical steps in developing a program that maximizes the possibility of success.

Our results show that after only four modules confidence in genetics skills had reached or were near levels observed at the completion of the curriculum, raising the possibility that a subset of modules, including those that cover foundational genetics issues, might achieve the desired results. However, we cannot know whether sustained improvements would have occurred with fewer modules; reducing the number of modules might result in fewer opportunities for reinforcement and decrease the likelihood of developing an ongoing community of practice. 
Table 3 Percentage of participants reporting that they planned to change practice as a result of each Medicine's Future module and percentage of participants reporting that they had changed practice and engaged in other genetics-related activities 6 months after completing module 10

\begin{tabular}{|c|c|c|}
\hline \multicolumn{3}{|c|}{ Percent of participants planning practice change } \\
\hline Module 1 & 88.9 & \multirow{3}{*}{$\begin{array}{l}\text { Examples of planned practice change } \\
\text { - Improved and/or more frequent collection of family history } \\
\text { information }\end{array}$} \\
\hline Module 2 & 80.7 & \\
\hline Module 3 & 80.0 & \\
\hline Module 4 & 85.0 & - More frequent genetic test ordering \\
\hline Module 5 & 83.3 & - More clinically appropriate genetic test ordering \\
\hline Module 6 & 85.7 & - More frequent consultation with and referral to genetic counselors \\
\hline Module 7 & 82.4 & - More self-initiated learning about genetics \\
\hline Module 8 & 73.3 & - Prescribing medications more carefully \\
\hline Module 9 & 50.0 & - Using family history information more effectively \\
\hline Module 10 & 85.7 & - Talking to patients about genetics more often \\
\hline \multicolumn{3}{|c|}{ Percent of participants reporting that they had changed practice } \\
\hline Six months after module 10 & 92.3 & $\begin{array}{l}\text { Examples of practice change } \\
\text { - Improvements to family history collection } \\
\text { - Improved ability to counsel patients on genetics issues } \\
\text { - Improved recognition of when referral to genetics specialists is appropriate } \\
\text { - Better awareness of when and how genetics impacts disease } \\
\text { - How to interpret genetic test results }\end{array}$ \\
\hline \multicolumn{3}{|c|}{ Percent reporting that they had engaged in other activities that impact practice } \\
\hline Six months after module 10 & 92.3 & $\begin{array}{l}\text { Examples of other activities } \\
\text { - Reading more journal articles about genetics } \\
\text { - Attending genetics conferences and lectures } \\
\text { - Talking to colleagues about genetics issues more often }\end{array}$ \\
\hline
\end{tabular}

Additionally, the modules that are focused on specific conditions and testing (modules 5-9) may have provided particular benefit to participants who were in need of more specialized skills. The challenges of finding time, money, and experience to develop content in this way can be difficult to overcome. Partnering with education experts, such as those within institutional CME or medical/nursing education departments, is one way to address these challenges.

We designed Medicine's Future to maximize participant engagement with each other, the expert facilitator, and the content. Improvement of practice is most effectively accomplished through interactivity, which is best facilitated in small-group settings. ${ }^{21,22}$ The modular structure of the curriculum allows it to be effectively implemented in multiple locations, without incurring additional development costs. In this way, education developed to change practice can reach a large number of providers when widely implemented.

Our intervention succeeded in meeting ECH's desired outcomes, and we believe it could be successful in other provider populations. In general, Medicine's Future participants had a moderate amount of exposure to genetics prior to their involvement in the course, likely impacting their motivation to engage in genetics education. Despite this motivation, the precurriculum knowledge measures suggest that this engaged group still had significant educational needs. The structure of the course and its application of adult-learning best practices could be appropriate for a wide range of locations and provider groups. One challenge in other settings may be identifying physicians motivated to participate, especially given competing priorities.

\section{Limitations}

The design of this study was a pre- and postactivity comparison without a control group. It is possible that knowledge, skills, and confidence could have improved through increased awareness of genomics over the same time period due to other factors. However, the improvements demonstrated by participants directly following each module suggest that the modules themselves were responsible. Respondents to the 6-month follow-up survey were self-selected, and the $38 \%$ who responded were not representative of the larger participant group.

The data presented represent aggregate results from all participants completing postactivity assessments for each module. Changes in individual participant knowledge, confidence, and practice change were not assessed or reported, owing to the small number of participants who could be followed through every session and assurance to participants that only aggregate data would be used for analysis. Additionally, confidence in genetics-related skills, intention to change behavior, and 
long-term behavior change were measured using participant self-reporting mechanisms. Although some evidence indicates that self-reported confidence tends to be overestimated, ${ }^{37}$ the consistent confidence increases reported by participants suggest that Medicine's Future positively impacted their confidence in performing genetics-related skills. We do not know the case circumstances for each genetic counseling referral that occurred during Medicine's Future, so it is not possible to determine whether the increased number of referrals reflected improved awareness of the availability and utility of genetic counseling, better recognition of cases for which genetic counseling was indicated, or both. Direct measurement of participants' behavior by analyzing electronic medical record information about familyhistory collection, genetic test ordering, and follow-up patient management or assessment using standardized patients ${ }^{38}$ would be ideal to determine whether the course facilitated integration of genomic practice into the clinic and improvement of skills.

\section{CONCLUSIONS}

As the national discussion about the challenges of integrating genomics into clinical practice continues, critical evaluation of the approaches being taken to move providers from awareness to implementation is needed. We report on the Medicine's Future experience as an example of applying best practices in adult learning to genomics education. These principles are well known but have not been implemented extensively for genomics education. Partnerships with organizations experienced in delivering effective education to clinicians should be undertaken as a step toward maximizing positive outcomes. Additionally, education that can be modified for providers with differing levels of experience and skill needs will help to prepare the broad health-care workforce for genomic medicine. The development and dissemination of quality, reusable education will further the goal of integrating genomics broadly and appropriately into clinical settings.

\section{SUPPLEMENTARY MATERIAL}

Supplementary material is linked to the online version of the paper at http://www.nature.com/gim

\section{ACKNOWLEDGMENTS}

The authors thank Robert Nussbaum and other facilitators of Medicine's Future, Abdallah Elias for his contribution to content development, participants of the course, and the GMl advisory board.

\section{DISCLOSURE}

Development and delivery of Medicine's Future were funded by El Camino Hospital under a grant to the National Coalition for Health Professional Education in Genetics (NCHPEG) and Genetic Alliance. For the described project, E.K.R., T.I.N., and J.A.S. were supported by NCHPEG; currently, E.K.R. and T.I.N. are supported by The Jackson Laboratory and J.A.S. is supported by the Health Resources and Services Administration (HRSA). E.K.R. received an honorarium for participation in an HRSA grant review committee. She has received travel reimbursement for speaking engagements in clinical settings but no honoraria. The work of K.J.T. is supported by the American Medical Association. She receives travel reimbursement for participation on the Institute of Medicine's Roundtable on Translating Genomic-Based Research for Health and the Veterans Administration National Research Advisory Council, as well as for speaking engagements at selected conferences; she does not accept honoraria for these activities. For the described project, L.O.D. was supported by a consulting contract with $\mathrm{ECH}$. She is currently an adviser to Vitagene, KineticDX, and Health Gorilla, for which she receives no compensation but has options to purchase future shares. She also receives travel reimbursement for speaking activities at selected conferences. For the described project, S.S. was supported by a consulting contract with NCHPEG. She is currently supported by a consulting contract with The Jackson Laboratory and by the Fullerton Genetics Center (Mission Health System). The work of J.C.O. is supported by Genetic Alliance and by grants to Genetic Alliance from HRSA and the Centers for Disease Control and Prevention. He receives travel reimbursement for speaking activities at selected conferences.

The authors declare no conflict of interest.

\section{REFERENCES}

1. Institute of Medicine Roundtable on Translating Genomic-Based Research for Health. Improving Genetics Education in Graduate and Continuing Health Professional Education: Workshop Summary. 2015. https://www.iom.edu/ Reports/2015/Improving-Genetics-Education-Graduate-Continuing-HealthProfessional-Education.aspx. Accessed 12 June 2015.

2. Mclnerney JD, Edelman E, Nissen T, Reed K, Scott JA. Preparing health professionals for individualized medicine. Pers Med 2012;9:529-537.

3. Feero WG, Green ED. Genomics education for health care professionals in the $21^{\text {st }}$ century. JAMA 2011;306:989-990.

4. Guttmacher AE, Porteous ME, Mclnerney JD. Educating health-care professionals about genetics and genomics. Nat Rev Genet 2007;8: 151-157.

5. Mikat-Stevens NA, Larson IA, Tarini BA. Primary-care providers' perceived barriers to integration of genetics services: a systematic review of the literature. Genet Med 2015;17:169-176.

6. Suther $S$, Goodson P. Barriers to the provision of genetic services by primary care physicians: a systematic review of the literature. Genet Med 2003;5:70-76.

7. Klitzman R, Chung W, Marder K, et al. Attitudes and practices among internists concerning genetic testing. J Genet Couns 2013;22:90-100.

8. Baars MJ, Henneman L, Ten Kate LP. Deficiency of knowledge of genetics and genetic tests among general practitioners, gynecologists, and pediatricians: a global problem. Genet Med 2005;7:605-610.

9. Bellcross CA, Kolor K, Goddard KA, Coates RJ, Reyes M, Khoury MJ. Awareness and utilization of BRCA1/2 testing among U.S. primary care physicians. Am J Prev Med 2011;40:61-66.

10. Brierley KL, Campfield D, Ducaine W, et al. Errors in delivery of cancer genetics services: implications for practice. Conn Med 2010;74:413-423.

11. Houwink EJ, van Luijk SJ, Henneman L, van der Vleuten C, Jan Dinant G, Cornel MC. Genetic educational needs and the role of genetics in primary care: a focus group study with multiple perspectives. BMC Fam Pract $2011 ; 12: 5$.

12. Vig HS, Armstrong J, Egleston BL, et al. Cancer genetic risk assessment and referral patterns in primary care. Genet Test Mol Biomarkers 2009;13: 735-741.

13. Blazer KR, Macdonald DJ, Culver JO, et al. Personalized cancer genetics training for personalized medicine: improving community-based healthcare through a genetically literate workforce. Genet Med 2011;13:832-840.

14. Carroll JC, Wilson BJ, Allanson J, et al. Genetikit: a randomized controlled trial to enhance delivery of genetics services by family physicians. Fam Pract 2011;28:615-623.

15. National Coalition for Health Professional Education in Genetics. Genetics in the Physician Assistant's Practice. 2008. http://www.nchpeg.org/pa. Accessed 27 March 2015. 
16. Kuo GM, Lee KC, Ma JD. Implementation and outcomes of a live continuing education program on pharmacogenomics. Pharmacogenomics 2013;14: 885-895.

17. Nissen SE. Reforming the continuing medical education system. JAMA 2015;313:1813-1814.

18. Grimshaw JM, Shirran L, Thomas R, et al. Changing provider behavior: an overview of systematic reviews of interventions. Med Care 2001;39(suppl 2): $112-145$.

19. Raza A, Coomarasamy A, Khan KS. Best evidence continuous medical education. Arch Gynecol Obstet 2009;280:683-687.

20. Frenk J, Chen L, Bhutta ZA, et al. Health professionals for a new century: transforming education to strengthen health systems in an interdependent world. Lancet 2010;376:1923-1958.

21. Davis D, O'Brien MA, Freemantle N, Wolf FM, Mazmanian P, Taylor-Vaisey A. Impact of formal continuing medical education: do conferences, workshops, rounds, and other traditional continuing education activities change physician behavior or health care outcomes? JAMA 1999;282:867-874.

22. Cervero RM, Gaines JK; for the Accreditation Council for Continuing Medical Education. Effectiveness of Continuing Medical Education: Updated Synthesis of Systematic Reviews. 2014. http://www.accme.org/sites/default/files/2014 Effectiveness_of_Continuing_Medical_Education_Cervero_and_Gaines_0.pdf. Accessed 18 March 2014.

23. Accreditation Council for Continuing Medical Education. 2014 ACCME Annual Report. http://www.accme.org/sites/default/files/630_20150707 2014 Annual_Report.pdf. Accessed 30 July 2015.

24. Merrill MD. First principles of instruction. Educ Technol Res Dev 2002;50:43-59.

25. Merrill MD. First principles of instruction: a synthesis. In: Reiser RA, Dempsey JV (eds). Trends and Issues in Instructional Design and Technology, 2nd edn. Merrill/Prentice-Hall: Upper Saddle River, NJ, 2006.

26. Cervero, RM. Lifespan professional development through practice-based education. Presented at the meeting of the Advisory Committee on Interdisciplinary, Community-Based Linkages, Rockville, MD, 27-28 January 2011.

27. Davis D, Galbraith R; American College of Chest Physicians Health and Science Policy Committee. Continuing medical education effect on practice performance: effectiveness of continuing medical education: American College of Chest Physicians Evidence-Based Educational Guidelines. Chest 2009;135(suppl 3):42S-48S.
28. Bloom BS. Effects of continuing medical education on improving physician clinical care and patient health: a review of systematic reviews. Int J Technol Assess Health Care 2005;21:380-385.

29. Marinopoulos SS, Dorman T, Ratanawongsa N, et al. Effectiveness of continuing medical education. Evid Rep Technol Assess 2007;149:1-69.

30. Chickering AW, Gamson ZF. Seven principles for good practice in undergraduate education. In: Chickering AW, Gamson ZF, (eds). Applying the Seven Principles for Good Practice in Undergraduate Education. Jossey-Bass: San Francisco, CA, 1991:63-69.

31. Collier KG. Peer-group learning in higher education: the development of higherorder skills. Stud High Educ 1980;5:55-62.

32. Blazer KR, Christie C, Uman G, Weitzel JN. Impact of web-based case conferencing on cancer genetics training outcomes for community-based clinicians. J Cancer Educ 2012;27:217-225.

33. Carroll JC, Blaine S, Permaul J, et al. Efficacy of an educational intervention on family physicians' risk assessment and management of colorectal cancer. J Community Genet 2014;5:303-311.

34. Watson E, Clements $A$, Yudkin $P$, et al. Evaluation of the impact of two educational interventions on GP management of familial breast/ovarian cancer cases: a cluster randomised controlled trial. Br J Gen Pract 2001;51: $817-821$.

35. Stone R, Cooper S, Cant R. The value of peer learning in undergraduate nursing education: a systematic review. ISRN Nurs 2013;2013:930901.

36. Houwink EJ, van Teeffelen SR, Muijtjens AM, et al. Sustained effects of online genetics education: a randomized controlled trial on oncogenetics. Eur J Hum Genet 2014;22:310-316.

37. Moore DA, Healy PJ. The trouble with overconfidence. Psychol Rev 2008:115:502-517.

38. Houwink EJ, Muijtjens AM, van Teeffelen SR, et al. Effectiveness of oncogenetics training on general practitioners' consultation skills: a randomized controlled trial. Genet Med 2014;16:45-52.

39. Greeno JG, Collins A, Resnick LB. Cognition and learning. In: Berliner DC, Calfee RC (eds). Handbook of Educational Psychology. Macmillan: New York, 1996:15-46.

40. Wilson BG, Myers KM. Situated in theoretical and practical context. In: Jonassen DH, Land SM (eds.). Theoretical Foundations of Learning Environments. Erlbaum: Mahwah, NJ, 2000:15-18. 